\title{
Enhancement of the nucleation of smooth and dense nanocrystalline diamond films by using molybdenum seed layers
}

\author{
J. G. Buijnsters, ${ }^{1,2, a)}$ L. Vázquez, ${ }^{3}$ G. W. G. van Dreumel, ${ }^{2}$ J. J. ter Meulen, ${ }^{2}$ \\ W. J. P. van Enckevort, ${ }^{2}$ and J. P. Celis ${ }^{1}$ \\ ${ }^{1}$ Department of Metallurgy and Materials Engineering, Katholieke Universiteit Leuven, Kasteelpark \\ Arenberg 44, B-3001 Leuven, Belgium \\ ${ }^{2}$ Institute for Molecules and Materials, Radboud University Nijmegen, Heijendaalseweg 135, \\ 6525 AJ Nijmegen, The Netherlands \\ ${ }^{3}$ Instituto de Ciencia de Materiales de Madrid (ICMM-CSIC), Cantoblanco, C/Sor Juana Inés de la Cruz 3 , \\ 28049 Madrid, Spain
}

(Received 16 August 2010; accepted 25 September 2010; published online 19 November 2010)

A method for the nucleation enhancement of nanocrystalline diamond (NCD) films on silicon substrates at low temperature is discussed. A sputter deposition of a Mo seed layer with thickness $50 \mathrm{~nm}$ on $\mathrm{Si}$ substrates was applied followed by an ultrasonic seeding step with nanosized detonation diamond powders. Hot-filament chemical vapor deposition (HF-CVD) was used to nucleate and grow NCD films on substrates heated up at $550{ }^{\circ} \mathrm{C}$. The nucleation of diamond and the early stages of NCD film formation were investigated at different methane percentages in methane/ hydrogen gas mixtures by atomic force microscopy, micro-Raman spectroscopy, scanning electron microscopy, and grazing incidence $\mathrm{x}$-ray analyses in order to gain specific insight in the nucleation process of NCD films. The nucleation kinetics of diamond on the Mo-coated Si substrates was found to be up to ten times higher than on blank Si substrates. The enhancement of the nucleation of diamond on thin Mo interlayers results from two effects, namely, (a) the nanometer rough Mo surface shows an improved embedding of ultrasonically introduced nanosized diamond seeds that act as starting points for the diamond nucleation during HF-CVD and (b) the rapid carbonization of the Mo surface causes the formation of $\mathrm{Mo}_{2} \mathrm{C}$ onto which diamond easily nucleates. The diamond nucleation density progressively increases at increasing methane percentages and is about 5 $\times 10^{10} \mathrm{~cm}^{-2}$ at $4.0 \%$ methane. The improved nucleation kinetics of diamond on Mo interlayers facilitates the rapid formation of NCD films possessing a very low surface roughness down to $\sim 6 \mathrm{~nm}$, and allows a submicron thickness control. (c) 2010 American Institute of Physics.

[doi:10.1063/1.3506525]

\section{INTRODUCTION}

Diamond has long been considered the material of choice for many technological applications because of its superior mechanical, optical, thermal, and electrical properties. ${ }^{1,2}$ With the rapid progress on laboratory synthesis of polycrystalline diamond by chemical vapor deposition (CVD), numerous applications have been reported till date., Polycrystalline diamond thin films are already utilized as hard and wear-resistant coatings, microwave and infrared windows, heat spreaders, and loudspeaker tweeters, for example. $^{3,4}$ However, several major problems associated with diamond CVD still remain, and need to be solved to enlarge the scope of applications for which diamond will indeed become the material of choice. The synthesis of large single-crystal diamonds and effective n-doped diamond materials, the high deposition temperature typically above $700{ }^{\circ} \mathrm{C}$, and the basically low growth rate of diamond of typically $1 \mu \mathrm{m} / \mathrm{h}$ using standard CVD methods are the main hurdles the scientific community is facing these days. ${ }^{1}$

Minimizing the surface roughness of CVD diamond films is a prerequisite in many present and future applica-

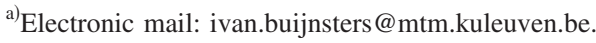

tions too. Obviously, the most effective approach is to synthesize diamond films with nanometer-sized grains ( $\leq 100 \mathrm{~nm}$ ). Research activities on nanograined, polycrystalline diamond have increased rapidly, and new synthesis methods of nanocrystalline ${ }^{5-7}$ and ultrananocrystalline ${ }^{8,9}$ diamond films have been developed. These two types of nanostructured diamond can be distinguished based on their growth chemistry, microstructure, and materials properties. Nanocrystalline diamond (NCD) films grow in hydrogenrich CVD environments, and so-called ultrananocrystalline diamond (UNCD) layers are generally synthesized in argonrich, hydrogen-poor gas mixtures. ${ }^{5}$ UNCD is synthesized due to a high renucleation rate during growth and generally consists of crystalline diamond grains of $2-5 \mathrm{~nm}$ in size with a relatively high fraction of $s p^{2}$-bonded carbon connecting the grains. Therefore, UNCD suffers from a poor thermal conductivity, and is a strongly light absorbing material. NCD grows typically at initially high nucleation site densities. The diamond grain size can differ from the diameter of the nucleating diamond particles, which are typically several nanometers large, up to about $150 \mathrm{~nm}$ at the growing film surface depending on the thickness of the NCD films and the applied CVD process conditions. NCD films have significantly lower 
amounts of $s p^{2}$-bonded carbon trapped at defects or grain boundaries as compared to UNCD and, importantly, NCD is highly transparent and thermally conductive.

The synthesis of extremely smooth, continuous nanodiamond layers with high film conformality on complex-shaped, three-dimensional patterned substrates is of large interest for the development of many diamond-based microelectromechanical systems (MEMS). Different seeding and substrate pretreatment techniques have been established to enhance the nucleation and continuity of NCD and UNCD films. ${ }^{10-14}$ The most widely applied substrate seeding method consists of an ultrasonic treatment in a suspension of diamond powders. ${ }^{15}$ Extremely high nucleation densities $\left(\sim 10^{11}\right.$ sites $\left./ \mathrm{cm}^{2}\right)$ have been reported on using monodispersed nanometer-sized diamond particles in aqueous solutions ${ }^{16}$ and slurries in dimethylsulfoxide. ${ }^{17}$ Also, the use of so-called ultradispersed nanodiamond particles buried under a sol-gel $\mathrm{TiO}_{2}$ layer resulted in an effective nucleation of NCD films. ${ }^{18}$ Surprisingly, only few works reported on the use of metallic nucleation layers. In many earlier studies on the deposition of diamond thin films on ferrous and cemented carbide substrates, metallic interlayers were already employed to suppress the large uptake of carbon, to suppress the outdiffusion of highly reactive $\mathrm{Fe}$ and $\mathrm{Co}$ atoms, and to improve the adhesion of the diamond films on the substrate. ${ }^{19-24}$ Only recently, the use of metallic nucleation layers for the synthesis of UNCD films was given special attention. It has been shown that thin surface layers of $\mathrm{W},{ }^{10} \mathrm{~W}-\mathrm{Al},{ }^{25} \mathrm{Ti}^{26}$ and $\mathrm{Mo}$ (Refs. 27 and 28) promote the nucleation of NCD and UNCD but there is still a limited knowledge on the nucleation characteristics and early stage formation of NCD and UNCD films.

In this work, we studied the enhancement of the nucleation and growth of NCD films by using Mo seed layers in order to gain specific insight in the diamond nucleation process. We aimed at the rapid formation of smooth and dense NCD films at low substrate temperature $\left(550{ }^{\circ} \mathrm{C}\right)$ to deal with the hurdles of the commonly high deposition temperature and low nucleation and growth rates associated with diamond CVD. Especially for the conventional hot-filament CVD (HF-CVD) process without Ar stock gas, it is difficult to obtain a sufficiently high diamond nucleation density to produce smooth NCD films at low substrate temperature. ${ }^{29}$

\section{EXPERIMENTAL SECTION}

\section{A. Materials deposition and substrate pretreatment}

Molybdenum seed layers of $50 \mathrm{~nm}$ thickness were deposited onto silicon (100) wafers by rf sputtering at $5 \mathrm{mbar}$ in an argon flow of 60 SCCM (SCCM denotes cubic centimeter per minute at STP) and an rf power of $500 \mathrm{~W}$. Nanostructured diamond was deposited on Mo-coated Si wafers using a home-built HF-CVD reactor. The following deposition parameters were maintained constant throughout the entire study: a substrate temperature of $550{ }^{\circ} \mathrm{C}$, a filament temperature of $2200{ }^{\circ} \mathrm{C}$, a pressure of $15 \mathrm{mbar}$, a filament-tosubstrate distance of $10 \pm 2 \mathrm{~mm}$, and a total gas flow of 303 SCCM. The methane and hydrogen flows were varied between 3 and 12 SCCM and 300 and 291 SCCM, respectively.
That resulted in a systematic variation in the methane percentage from $1.0 \%$ to $4.0 \%$ as indicated in the growth experiments reported below. A precarburized tantalum filament coil of $0.5 \mathrm{~mm}$ diameter was used throughout. The filament and substrate temperatures were monitored with an optical pyrometer (model M90-V, Mikron Infrared Inc.) and a K-type thermocouple placed at the back side of the substrates, respectively. The substrate temperature $\left(550 \pm 15{ }^{\circ} \mathrm{C}\right.$ ) was maintained using a PID controller (model 2416, Eurotherm Ltd.) with an induction heating system (model TR1, Cheltenham Induction Heating Ltd.) for heating up the Mo-substrate holder combined with an active water cooling of the same. As a seeding pretreatment, the uncoated and Mo-coated $\mathrm{Si}$ wafers were ultrasonically treated in a suspension of nanodiamond powders of detonation origin (Sigma-Aldrich, particle size $<10 \mathrm{~nm}$ ) in isopropanol for 1 $\mathrm{h}$, followed by a rinsing in pure isopropanol for $1 \mathrm{~min}$.

\section{B. Characterization}

Scanning electron microscopy (SEM; JEOL JSM 6330 F) and atomic force microscopy (AFM; Nanoscope IIIa from Veeco and PicoSPM II Pico+ from Agilent) operated in tapping mode with silicon cantilevers (nominal radius of $10 \mathrm{~nm}$ ) were used to characterize the surface topography of the samples before and after diamond nucleation and NCD film growth. Microstructural analyses of the diamond deposits were performed by micro-Raman spectroscopy at room temperature using an Ar-ion laser (514.5 nm) at $800-2000 \mathrm{~cm}^{-1}$ (Renishaw System 1000) using a $50 \times$ objective with a spot size of about $2 \mu \mathrm{m}$. Grazing incidence x-ray diffraction (XRD) and $\mathrm{x}$-ray reflectometry (XRR) were performed to study the (crystalline) phases formed at the substrate surface during diamond deposition. $\mathrm{Cu} K_{\alpha}$ radiation $(40 \mathrm{kV}, 40 \mathrm{~mA})$ was used for both types of measurements. XRD patterns were recorded at constant grazing angle of $6^{\circ}$ and $2 \theta$-angles between $6^{\circ}$ and $130^{\circ}$ with a step size of $0.02^{\circ}$ and a step time of $10 \mathrm{~s}$. XRR measurements were performed at $2 \theta$ ranging between $0.4^{\circ}$ and $2^{\circ}$ using a step size of $0.005^{\circ}$ and a step time of $2 \mathrm{~s}$. The XRR data were analyzed with the X'Pert reflectivity program to extract density and thickness of the molybdenum seed layers before and after diamond nucleation.

\section{RESULTS AND DISCUSSION}

\section{A. Substrate seeding and nucleation of diamond \\ 1. Diamond nucleation site density}

SEM images of the diamond nucleation and early stage formation of NCD films on preseeded Mo-coated silicon $(\mathrm{Mo} / \mathrm{Si})$ and preseeded blank silicon $(\mathrm{Si})$ are shown in Fig. 1. The significant increase in the diamond nucleation site densities on $\mathrm{Mo} / \mathrm{Si}$ substrates is evident for the two selected growth conditions, namely a methane-to-hydrogen gas mixture of $1.0 \%$ [Figs. 1(a) and 1(b)] and 2.0\% [Figs. 1(c)-1(f)]. The diamond nucleation site density up to nearly $10^{10} \mathrm{~cm}^{-2}$ and a surface coverage of $\sim 55 \%$ on $\mathrm{Mo} / \mathrm{Si}$ substrates are an order of magnitude higher than on blank $\mathrm{Si}$ after a $20 \mathrm{~min}$ HF-CVD diamond processing using $1.0 \% \mathrm{CH}_{4} / \mathrm{H}_{2}$ [Figs. 

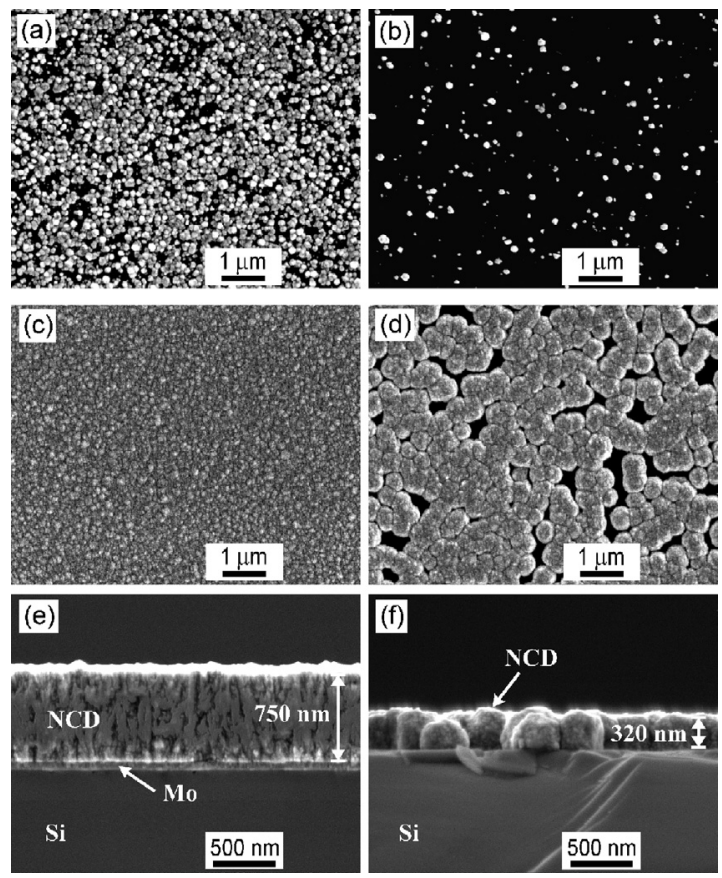

FIG. 1. Plan-view SEM of Mo/Si (a) and blank silicon (b) surfaces after diamond nucleation by HF-CVD for 20 min using $1.0 \% \mathrm{CH}_{4} / \mathrm{H}_{2}$. Plan-view and cross-sectional SEM of NCD layers deposited for 20 min using $2.0 \%$ $\mathrm{CH}_{4}$ on $\mathrm{Mo} / \mathrm{Si}[(\mathrm{c})$ and (e)] and blank silicon [(d) and (f)], respectively. A 1 $\mathrm{h}$ ultrasonic seeding pretreatment with nanodiamond powders was applied for all samples prior to HF-CVD processing.

1(a) and 1(b)]. The enhanced diamond nucleation kinetics on a Mo seed layer induces the development of more uniform and much smoother microcrystalline diamond films and this even after prolonged growth times (not shown). ${ }^{28}$ For HFCVD processing using higher methane concentrations, e.g., $2.0 \%$, the partial pressure of carbon in the gas phase increases accordingly. The higher supersaturation and, thus, driving force for diamond deposition, then lead to an enhanced diamond deposition kinetics. This can be derived from Figs. 1(c) and 1(d), which display the top-view SEM images of the NCD film (formation) on the $\mathrm{Mo} / \mathrm{Si}$ and $\mathrm{Si}$ substrates after growth for $20 \mathrm{~min}$ in $2.0 \% \mathrm{CH}_{4} / \mathrm{H}_{2}$. On blank $\mathrm{Si}$, the initial number site density of diamond nuclei is comparable for $1.0 \% \mathrm{CH}_{4} / \mathrm{H}_{2}$ [Fig. 1(b)] and $2.0 \% \mathrm{CH}_{4} / \mathrm{H}_{2}$ [Fig. 1(d)]. However, the significantly higher surface coverage of diamonds deposited at $2.0 \% \mathrm{CH}_{4} / \mathrm{H}_{2}$ can be explained by the larger volume fraction of the diamond deposits, which are aggregates of nanograined diamond with a high degree of secondary nucleation and/or twinning. On the Mo/Si substrates, the effect of increasing $\mathrm{CH}_{4} / \mathrm{H}_{2}$ ratio is even more pronounced. In addition, the number site density of diamond nuclei onto which the nanograined diamond aggregates were initially formed, appears to be higher than at lower $\mathrm{CH}_{4} / \mathrm{H}_{2}$ ratio. A very uniform and closed NCD film is already formed after a HF-CVD processing for only $20 \mathrm{~min}$ [Fig. 1(c)]. The faster deposition kinetics of NCD on a Mo seed layer results in the formation of much thicker NCD films as well. A crosssectional SEM analysis reveals the development of a relatively thick $(\sim 750 \mathrm{~nm})$ and smooth (rms roughness $\sim 40 \mathrm{~nm}$ ) NCD film on the Mo-coated silicon substrate [Fig. 1(e)]. On the other hand, only semispherical NCD nucleation

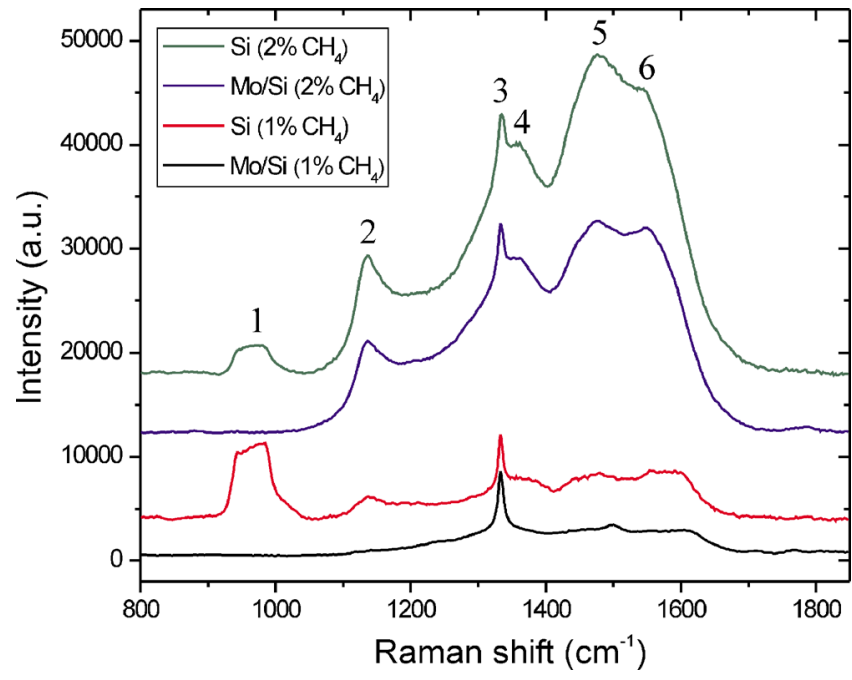

FIG. 2. (Color online) Raman spectra recorded on $\mathrm{Mo} / \mathrm{Si}$ and blank silicon substrate surfaces after HF-CVD processing for $20 \mathrm{~min}$ using $1.0 \%$ and $2.0 \% \mathrm{CH}_{4}$. The Raman signals numbered 1-6 correspond to the second order signal from the silicon substrate (1) and to signals from t-PA (2 and 5), diamond (3), and the D-band (4) and G-band (6) of graphite, respectively.

clusters about $320 \mathrm{~nm}$ in size with some degree of coalescence are found on blank $\mathrm{Si}$ [Fig. 1(f)]. Interfacial voids and open areas observed in-between these NCD clusters result from the nonuniform and relatively sluggish nucleation in absence of a Mo seed layer.

\section{Crystalline development}

Note that a higher percentage of $\mathrm{CH}_{4}$, namely, $2.0 \%$ in $\mathrm{H}_{2}$ [Figs. 1(c)-1(f)], also leads to the formation of nanostructured diamond deposits with a lower crystalline order. This type of NCD is commonly referred to as cauliflower- or ballas-type growth morphology. ${ }^{5,29}$ On the other hand, the diamond crystallites grown with a methane percentage of $1.0 \%$ appear to be still well-faceted. The higher $\mathrm{CH}_{4}$-to- $\mathrm{H}_{2}$ ratio presumably induces crystal twinning, and the incorporation of nondiamond phases such as graphite and amorphous carbon. ${ }^{5,30}$ Raman spectra recorded on diamond deposits after HF-CVD growth for $20 \mathrm{~min}$ with methane percentages of $1.0 \%$ and $2.0 \%$ are shown in Fig. 2. The Raman spectra are characterized by six clear signals labeled from 1 to 6 with increasing Raman shift. The diamond peak (3) is centered at $1333 \mathrm{~cm}^{-1}$ and the Raman signals corresponding to the so-called D-band (4) and G-band (6) of graphite $^{31}$ are observed at $1365 \mathrm{~cm}^{-1}$ and $1590 \mathrm{~cm}^{-1}$, respectively. At $1136 \mathrm{~cm}^{-1}$ (2) and about $1480 \mathrm{~cm}^{-1}$ (5) signals related to trans-polyacetylene (t-PA) at grain boundaries and surfaces can be distinguished. ${ }^{31}$ The second order signal from the silicon substrate $\left(1 \sim 970 \mathrm{~cm}^{-1}\right)$ is observed on the blank Si substrate only due to the limited surface coverage and relatively small quantities of deposited diamond. In summary, two important trends appear from the Raman analyses: (a) the higher methane percentage gives rise to relatively stronger signals related to nondiamond carbon phases ( $\mathrm{t}-\mathrm{PA}$ and graphite) and (b) the carbon-related Raman signals from diamond deposits on blank $\mathrm{Si}$ and $\mathrm{Mo} / \mathrm{Si}$ substrates are very similar. The latter observation implies that the presence of the Mo seed layer improves the kinetics of diamond nucle- 
(a)

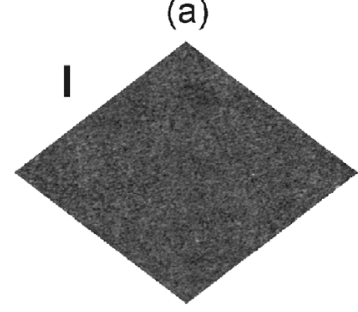

(c)

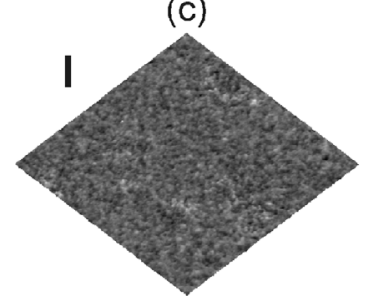

(b)

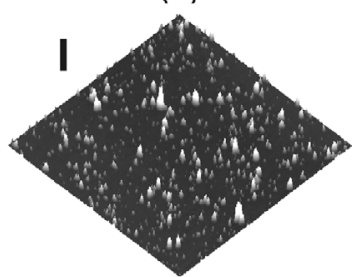

(d)

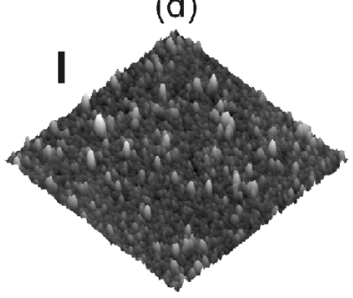

FIG. 3. $2 \times 2 \mu \mathrm{m}^{2}$ tapping mode AFM images of blank silicon wafer (a), ultrasonically seeded silicon substrate (b), and $\mathrm{Mo} / \mathrm{Si}$ surface before (c) and after (d) ultrasonic seeding pretreatment in a suspension of nanodiamond powder. The vertical bars represent $50 \mathrm{~nm}$.

ation and diamond film formation, but does not deteriorate the carbon phase purity of the diamond deposits as such. On the contrary, the relative Raman intensities of t-PA and graphitic carbon are somewhat lower on Mo seed layers.

\section{Seed density}

A detailed AFM analysis was performed to investigate topographical effects resulting from the surface modification of the silicon substrate by sputter deposition of Mo and the ultrasonic seeding with nanodiamond powders. Figure 3 shows AFM images $\left(2 \times 2 \mu \mathrm{m}^{2}\right)$ of the silicon wafer and Mo-coated silicon substrate before and after ultrasonication in a nanodiamond powder suspension. The untreated silicon wafer [Fig. 3(a)] is extremely smooth (root mean square, rms, roughness of $0.1-0.2 \mathrm{~nm}$ ). It reveals a strong precipitation of nanodiamond seeds [Fig. 3(b)] after ultrasonic seeding for $1 \mathrm{~h}$. A relatively high number density $\left(\sim 10^{10} \mathrm{~cm}^{-2}\right)$ of nanosized diamond seeds is observed.

On the other hand, the $50 \mathrm{~nm}$ thick Mo seed layer (rms roughness $\sim 0.4 \mathrm{~nm}$ ) displays an irregular, granular structure of features with lateral dimensions in the range $10-40 \mathrm{~nm}$ [Fig. 3(c)]. After ultrasonic seeding [Fig. 3(d)], the surface roughness of the Mo-coated silicon significantly increased ( $\sim 4.4 \mathrm{~nm}$ ) due to the effective embedding of nanodiamond aggregates that adhere well to the relatively rough Mo surface via van der Waals interactions. ${ }^{12}$ Although it is difficult to unambiguously distinguish the diamond seeds from the Mo surface grains, the lateral sizes of the diamond seeds seem to vary from about $100 \mathrm{~nm}$ down to less than $10 \mathrm{~nm}$, which corresponds to the core nanodiamond particle size. The average density of nanodiamond seeds is in the order of $2 \times 10^{10}$ nanoparticles $/ \mathrm{cm}^{2}$. This will be a lower limit for the nucleation of diamond during the subsequent diamond CVD growth since multiple nucleation can take place at a single particle. ${ }^{12}$ The detected protrusions are likely agglomerates of nanosized diamond core particles that might separate into even smaller particles due to etching by atomic hydrogen during the HF-CVD process. ${ }^{12}$ Houška et al. ${ }^{32}$ re- cently reported that detonation nanodiamond particles have an extremely strong interaction with metallic targets, so likely diamond seed particles with dimensions less than 10 $\mathrm{nm}$ stick better at the metallic Mo surface than at the smoother Si surface. In addition, the Mo surface is much softer than the blank Si substrate, and the Mo/Si substrate will deform more easily under the ultrasonic action of heavily impacting detonation nanodiamond particles. ${ }^{15}$ Next to the expected higher degree of geometrical interlocking of nanodiamond seeds on the rougher Mo film surface, the plastic deformation of the exposed $\mathrm{Mo} / \mathrm{Si}$ substrate surface might also contribute to a more efficient embedding of nanosized diamond seeds as compared to blank silicon.

\section{Diamond nucleation process}

In all diamond CVD processes, the nucleation of diamond crystals is mainly determined by the availability of diamond seeds. These seeds are typically generated at the substrate surface by ultrasonication using diamond powders and they act as starting points for the nucleation of diamond from the gas phase. However, from classical nucleation theory ${ }^{33}$ it is known that the critical nucleus size becomes smaller at increasing supersaturation. This implies that at increasing supersaturation (i.e., methane percentage), diamond seeds of progressively smaller dimensions become active sites for diamond nucleation. The nucleation of diamond on surface defects or on top of nondiamond carbon phases such as graphite or carbides will increase as well.

The formation of stable diamond nuclei as a function of the methane percentage was analyzed by ex situ AFM performed on shortly exposed substrate surfaces. In this way, the existence of any correlation between the density of ultrasonically applied nanosized diamond seeds on blank Si and $\mathrm{Mo} / \mathrm{Si}$ substrates and the site density of diamond nuclei during the early stages of NCD nucleation could be checked. A series of $2 \times 2 \mu \mathrm{m}^{2}$ AFM images of the diamond outgrowth after 2 min on preseeded Mo/Si and blank Si substrates obtained by using methane gas percentages of $2.0 \%, 3.0 \%$, and $4.0 \%$, is shown in Fig. 4.

It is evident that the nucleation of diamond proceeds much faster and in a more uniform way on Mo-coated silicon substrates [Figs. 4(a), 4(c), and 4(e)]. On using $2.0 \% \mathrm{CH}_{4}$, relatively large NCD clusters with an average diameter of about $100 \mathrm{~nm}$ are formed on Mo/Si substrates [Fig. 4(a)]. At increasing methane concentration, the average size of diamond nuclei decreases but the nuclei number density increases significantly so that almost completely closed NCD films are formed on Mo/Si substrates [Figs. 4(c) and 4(e)]. On the other hand, diamond nucleation on blank preseeded Si substrates does not result in significantly higher number densities of diamond nuclei at increasing methane flow. Only a slight increase up to about $4 \times 10^{9} \mathrm{~cm}^{-2}$ is noticed at a methane percentage of $4.0 \%$ [Fig. 4(f)]. A clear relation between the average size of the diamond nuclei and the methane flow was not noticed in the case of blank Si substrates.

Numerical data on the seeds or nucleation site density, the surface coverage, the rms surface roughness, and the surface skewness of the untreated, seeded, and several processed (i.e., after 2' nucleation) $\mathrm{Si}$ and $\mathrm{Mo} / \mathrm{Si}$ samples, are 
(a)

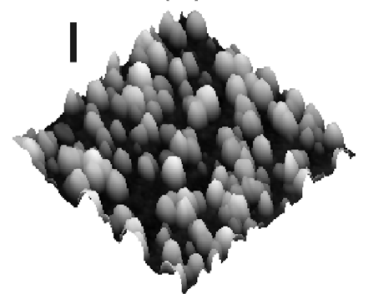

(c)

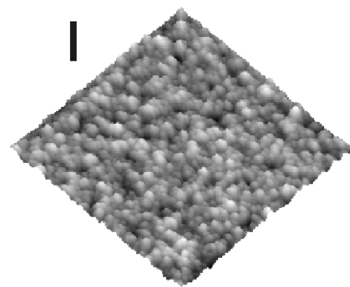

(e)
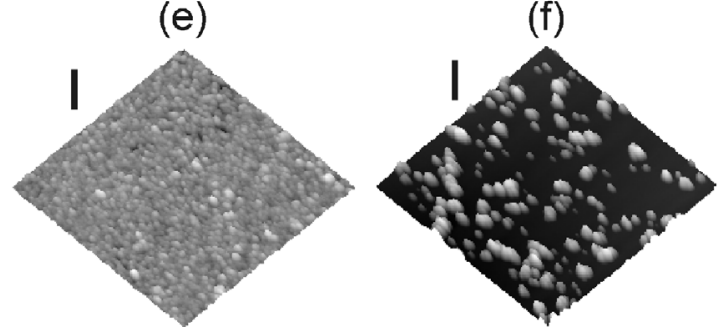

FIG. 4. $2 \times 2 \mu \mathrm{m}^{2}$ tapping mode AFM images of the nucleation of diamond on Mo/Si substrates [(a), (c), and (e)] and blank silicon [(b), (d), and (f)] after HF-CVD processing for 2 min using methane flows of $2.0 \%$ [(a) and (b)], 3.0\% [(c) and (d)], and 4.0\% [(e) and (f)]. The vertical bars correspond to $250 \mathrm{~nm}$.

summarized in Table I. These data were derived from AFM measurements done at three different locations on each sample surface, and the deduced relative errors are in the order of maximum $20 \%$.
The number site densities of diamond nuclei on blank $\mathrm{Si}$ substrates are somewhat lower, typically about 3 $\times 10^{9} \mathrm{~cm}^{-2}$, than the seeding density which is 1 $\times 10^{10} \mathrm{~cm}^{-2}$, and do not evolve notably with the methane percentage. On $\mathrm{Mo} / \mathrm{Si}$ substrates, the density of diamond nuclei progressively increases from $5 \times 10^{8} \mathrm{~cm}^{-2}$ up to $\sim 5$ $\times 10^{10} \mathrm{~cm}^{-2}$ at increasing methane flow from $1.5 \%$ up to $4.0 \%$, respectively. For HF-CVD done at methane percentages higher than or equal to $3.0 \%$, the density of nuclei becomes thus larger than the density of nanosized diamond seeds which was $\sim 2 \times 10^{10} \mathrm{~cm}^{-2}$. These observations imply that only a fraction of the diamond seeding particles serve as preferential sites for diamond nucleation at methane flows lower than 3.0\%. The tiniest diamond seeds, which are subcritical under these conditions, might even simply be etched away by the hydrogen radicals present in the reactive gas phase, and the remains of diamond seeds develop into larger nuclei. ${ }^{34}$ At methane flows equal to or higher than $3.0 \%$, diamond seeds of progressively smaller dimensions also act as starting points for diamond nucleation on the Mo/Si substrates. In addition, diamond nucleation can take place at nanoscale surface defects, such as scratches and pits, induced during the ultrasonic pretreatment. Moreover, diamond nucleation (using 2.0\% $\mathrm{CH}_{4} / \mathrm{H}_{2}$ ) on unseeded $\mathrm{Mo} / \mathrm{Si}$ substrates already leads to diamond nucleation site densities of about $1 \times 10^{9} \mathrm{~cm}^{-2}$, whereas it does not lead to detectable diamond nucleation on unseeded $\mathrm{Si}$ at all. This implies that the rapid formation of a carbide-based surface layer is another source for diamond nucleation, which is discussed in Sec. III B.

\section{Surface roughness and diamond nucleation site density}

A close analysis of Table I and Fig. 4 reveals that the rms surface roughness is mainly determined by the overall size of

TABLE I. rms surface roughness, surface skewness, seeds or nucleation number site density, and surface coverage for a series of samples investigated in this study. The data are derived from AFM measurements at three surface locations on each sample. The type of substrate material ( $\mathrm{Si}$ versus $\mathrm{Mo} / \mathrm{Si}$ ) is mentioned as well as the sample preparation conditions (ultrasonic seeding), and the applied methane percentage in the case of HF-CVD processed samples (i.e., after 2 min of diamond nucleation).

\begin{tabular}{|c|c|c|c|c|c|}
\hline $\begin{array}{l}\text { Substrate material } \\
\text { and sample preparation }\end{array}$ & $\begin{array}{c}\text { Methane } \\
\text { percentage } \\
(\%)\end{array}$ & $\begin{array}{l}\text { rms surface } \\
\text { roughness } \\
(\mathrm{nm})\end{array}$ & $\begin{array}{c}\text { Surface } \\
\text { skewness }\end{array}$ & $\begin{array}{l}\text { Diamond seeds }(*) \\
\text { or nuclei site density } \\
\qquad\left(\mathrm{cm}^{-2}\right)\end{array}$ & $\begin{array}{c}\text { Surface } \\
\text { coverage } \\
(\%)\end{array}$ \\
\hline $\mathrm{Si}$ & N/A & $0.1-0.2$ & 0.0 & N/A & N/A \\
\hline Seeded Si & N/A & 3.4 & 5.0 & $1 \times 10^{10}(*)$ & 10 \\
\hline \multicolumn{6}{|l|}{ Diamond nucleation } \\
\hline Seeded $\mathrm{Si}$ & 2.0 & 7.4 & 3.3 & $3 \times 10^{9}$ & 10 \\
\hline Seeded Si & 3.0 & 18.6 & 3.1 & $3 \times 10^{9}$ & 20 \\
\hline Seeded Si & 4.0 & 12.5 & 1.5 & $4 \times 10^{9}$ & 30 \\
\hline $\mathrm{Mo} / \mathrm{Si}$ & N/A & 0.4 & 0.3 & N/A & N/A \\
\hline Seeded $\mathrm{Mo} / \mathrm{Si}$ & N/A & 4.4 & 1.1 & $2 \times 10^{10}(*)$ & 15 \\
\hline \multicolumn{6}{|l|}{ Diamond nucleation } \\
\hline Unseeded Mo/Si & 2.0 & 3.3 & 0.9 & $1 \times 10^{9}$ & 2 \\
\hline Seeded Mo/Si & 1.5 & 2.9 & 7.6 & $5 \times 10^{8}$ & 10 \\
\hline Seeded Mo/Si & 2.0 & 48.2 & 0.5 & $4 \times 10^{9}$ & 60 \\
\hline Seeded $\mathrm{Mo} / \mathrm{Si}$ & 2.5 & 9.7 & -1.0 & $1 \times 10^{10}$ & 95 \\
\hline Seeded Mo/Si & 3.0 & 10.4 & 0.1 & $2 \times 10^{10}$ & 98 \\
\hline Seeded $\mathrm{Mo} / \mathrm{Si}$ & 3.5 & 11.4 & -0.2 & $\sim 3 \times 10^{10}$ & 97 \\
\hline Seeded $\mathrm{Mo} / \mathrm{Si}$ & 4.0 & 5.8 & -0.2 & $\sim 5 \times 10^{10}$ & 98 \\
\hline
\end{tabular}


the diamond nuclei, and not by their number density. Since the rms surface roughness alone is not adequate for assessing the surface topography as different surface profiles can exhibit similar roughness values, the surface skewness is also listed in Table I. The surface skewness is a statistical term describing the third central moment of the height values about the mean height and is a measure of the surface asymmetry. ${ }^{35,36}$ Positive values of the surface skewness are found for flat surfaces with peaks, whereas negative values are representative of bearing surfaces with holes. Values numerically greater than 1.0 may indicate extreme holes or peaks on surfaces. From Table I, it appears that the substrate seeding pretreatment and the nucleation of diamond both result in positive and numerically high surface skewness values. The surface skewness decreases again at increasing methane flows. In other words, less asymmetric height distributions are obtained at higher degrees of NCD film closure. Note that a nearly closed and extremely smooth NCD film (rms surface roughness $\sim 6 \mathrm{~nm}$; layer thickness $\sim 80 \mathrm{~nm}$ ) is already achieved on using a $\mathrm{CH}_{4} / \mathrm{H}_{2}$ gas mixture of $4.0 \%$ for $2 \mathrm{~min}$.

It is important to notice that the diamond nucleation site densities obtained on $\mathrm{Mo} / \mathrm{Si}$ substrates are typically one order of magnitude higher than the ones on blank Si substrates for identical HF-CVD process conditions. A diamond nucleation site density of $5 \times 10^{10} \mathrm{~cm}^{-2}$ is obtained at the highest methane flow investigated, namely, $4.0 \%$. This value is among the highest values reported in literature (i.e., $10^{11} \mathrm{~cm}^{-2}$ ) for the nucleation of NCD on silicon by microwave plasma-enhanced CVD at an elevated temperature of $700{ }^{\circ} \mathrm{C}$, and using a seeding step with monodispersed nanometer-sized diamond particles in aqueous solutions. ${ }^{16}$ Our study thus shows that the nucleation of diamond on ultrasonically preseeded Mo seed layers is very efficient, even on HF-CVD operated at low substrate temperature and not requiring the use of monodispersed nanodiamond particles.

\section{B. Carburization of the Mo seed layer}

In Fig. 5(a) are displayed the grazing incidence XRD plots recorded on the sputter-deposited $\mathrm{Mo} / \mathrm{Si}$ substrate (upper graph) and on the $\mathrm{Mo} / \mathrm{Si}$ sample (lower graph) after 2 min of diamond nucleation using $2.0 \% \mathrm{CH}_{4}$. The assputtered Mo seed layer is polycrystalline and is clearly identified by the corresponding (110), (200), (211), (220), (310), and (222) reflections. Apart from the sharp reflections at $2 \theta$ $=62.6^{\circ}$ and $82.6^{\circ}$ that originate from the trace $\mathrm{Cu} K_{\beta}$ radiation interacting with the single crystalline silicon substrate, two broad bands at $2 \theta=57.2^{\circ}$ and $86.6^{\circ}$ appear. Since the measurements were performed at room temperature, these bands are probably the result of thermal diffuse scattering caused by thermally excited lattice vibrations of the silicon substrate. ${ }^{37}$ After a diamond CVD processing of $2 \mathrm{~min}$, the Mo layer appears completely carburized. No reflections from Mo can be detected at all, and the reflections from $\mathrm{Mo}_{2} \mathrm{C}$ are predominant. A minor reflection at $2 \theta=43.9^{\circ}$ might be assigned to diamond (111). XRR was used to analyze the assputtered Mo layer thickness and the one after diamond
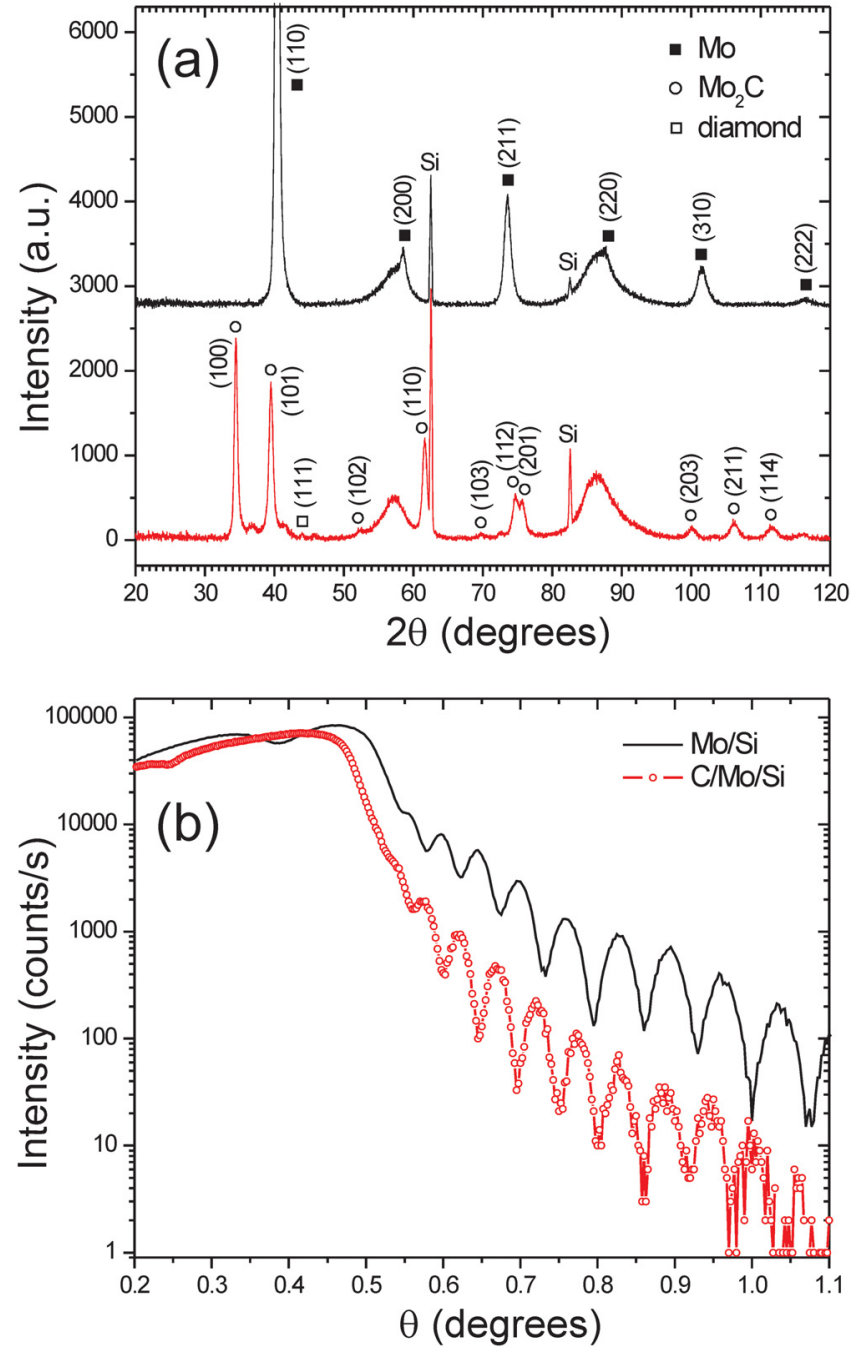

FIG. 5. (Color online) Grazing incidence XRD (a) and reflectometry (b) patterns recorded on $\mathrm{Mo} / \mathrm{Si}$ substrates before (upper scans) and after (lower scans) a diamond nucleation for 2 min using a $\mathrm{CH}_{4} / \mathrm{H}_{2}$ gas mixture of $2.0 \%$.

nucleation for 2 min using a methane flow of $2.0 \%$. The XRR plots of the corresponding samples are shown in Fig. 5(b). From the curve best fits, a film thickness of $53.2 \pm 0.4 \mathrm{~nm}$ was deduced for the as-sputtered Mo layer, and $62.5 \pm 0.2 \mathrm{~nm}$ after HF-CVD processing which corresponds to a thickness increase by nearly $20 \%$. From the XRR analysis it was also found that the indiffusion of carbon during the diamond CVD growth leads to a slightly lower density of the exposed Mo seed layer as compared to the assputtered one.

X-ray analyses clearly show that, even within the first 2 min of diamond nucleation, the Mo seed layer is completely carburized into a single-phase $\mathrm{Mo}_{2} \mathrm{C}$ layer. This results from the high diffusion coefficient of atomic carbon in molybdenum and $\mathrm{Mo}_{2} \mathrm{C},{ }^{38,39}$ even at the relatively low substrate temperature of $550{ }^{\circ} \mathrm{C}$. Molybdenum forms carbides much faster than silicon and, therefore, the formation of molybdenum carbide phases plays a key role in the enhanced nucleation of diamond on $\mathrm{Mo} / \mathrm{Si}$ substrates. In earlier studies, it was shown that the growth of diamond on Mo substrates usually proceeds along the formation of a relatively thick, intermediate $\mathrm{Mo}_{2} \mathrm{C}$ layer. ${ }^{40-44}$ The nucleation of diamond 

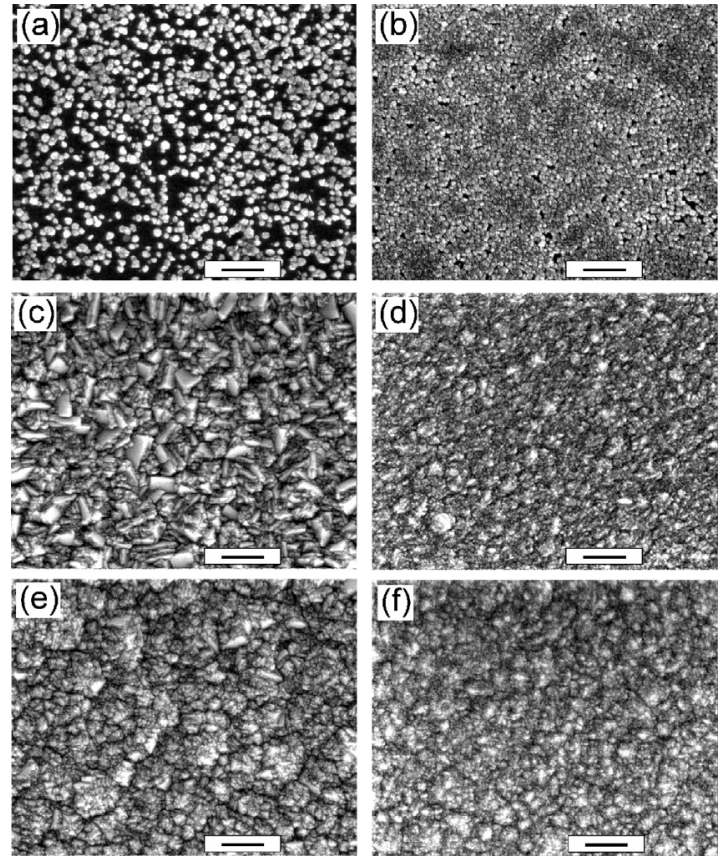

FIG. 6. Plan-view SEM of different stages of the NCD film formation on $\mathrm{Mo} / \mathrm{Si}$ surfaces using $\mathrm{CH}_{4} / \mathrm{H}_{2}$ gas flows of $2.0 \%$ (left column) and $3.0 \%$ (right column). (a) and (b), (c) and (d), and (e) and (f) correspond to HFCVD processing times of $2 \mathrm{~min}, 20 \mathrm{~min}$, and $80 \mathrm{~min}$, respectively. The scale bars represent $500 \mathrm{~nm}$.

typically takes place, once the intermediate $\mathrm{Mo}_{2} \mathrm{C}$ layer attains a critical thickness that can be several micrometers depending on the diamond CVD process conditions. Bahr et $a l .{ }^{45}$ showed that the accumulation of carbon leads to the formation of $\mathrm{C}-\mathrm{C}$ bonds within the molybdenum carbide layer and that the growth of diamond on top of Mo substrates starts only after an incubation time. This incubation period corresponds to the time necessary to develop a carbide layer and to saturate the surface of the carbide with carbon to promote diamond film growth. ${ }^{45}$ In the case of a $50 \mathrm{~nm}$ thick Mo layer, the complete carburization and the accumulation of carbon atoms onto the substrate surface, take place within $2 \mathrm{~min}$. This leads to an increased nucleation rate of diamond on top of the Mo-coated Si substrates. Chen et al. ${ }^{27}$ recently demonstrated by high-resolution transmission electron microscopy that the microwave assisted CVD growth of UNCD films on Mo coatings proceeds via the nucleation of UNCD on top of $\mathrm{Mo}_{2} \mathrm{C}, \mathrm{MoC}$, and possibly graphite. They also found that the diffusion of $\mathrm{C}$ inward the Mo coatings in combination with the outward diffusion of Si from the substrate, results in the local formation of $\mathrm{SiC}$ at the interface between Mo layer and Si substrate. The interdiffusion between the Mo layer and both the diamond film and the $\mathrm{Si}$ substrate, is expected to enhance the adhesion of the diamond film with the Si substrate.

\section{Growth of smooth NCD films}

The enhanced nucleation kinetics of diamond on the Mocoated $\mathrm{Si}$ substrates facilitates the rapid formation of dense and smooth NCD films. Various stages of the formation of NCD films using $2.0 \%$ and $3.0 \% \mathrm{CH}_{4}$ are shown in Fig. 6. Obviously, the diamond nucleation site density and surface coverage is significantly higher at higher methane percentage after a nucleation time of 2 min [Figs. 6(a) and 6(b)]. The coalescence of diamond nuclei leads to a complete film closure after deposition times of $5 \mathrm{~min}$ and $10 \mathrm{~min}$ on using $3.0 \%$ and $2.0 \% \mathrm{CH}_{4}$, respectively. It is well known that the smoothest nanograined diamond films are obtained for the highest primary nucleation site densities. ${ }^{46}$ We also observed that the improved diamond nucleation kinetics at the higher levels of carbon supersaturation results in the formation of significantly smoother NCD surfaces. For example, $750 \mathrm{~nm}$ thick NCD films obtained after HF-CVD processing for 20 min at $2.0 \%$ and $3.0 \%$ methane percentage [Figs. 6(c) and 6(d)] have an rms surface roughness of $47 \mathrm{~nm}$ and $22 \mathrm{~nm}$, respectively. The randomly oriented diamond crystalline facets are considerably larger for the NCD film grown at lower methane concentration [Fig. 6(c)]. On extending the deposition time, the NCD film surfaces become cauliflowerlike and smoother for HF-CVD processing using 3.0\% $\mathrm{CH}_{4}$ [Fig. 6(f)]. Important is to notice that the rms roughness of fully closed NCD films does nearly not vary with deposition time due to the continuous breaking up of diamond facets by twinning, the incorporation of nondiamond phases, and/or the renucleation of diamond.

Visible light micro-Raman spectroscopy analyses were performed to determine the carbon constituents of NCD deposits as a function of their deposition duration (Fig. 7). This analysis technique is very sensitive to slight differences in carbon bonding structures since visible photons preferentially excite the $\pi$ states. ${ }^{31}$ Therefore, visible light Raman spectroscopy is 50-230 times more sensitive to $s p^{2}$-bonded (graphitic) carbon than to $s p^{3}$-bonded (diamondlike) carbon. Minor differences in $s p^{2} / s p^{3}$ ratio of the diamond deposits can thus easily be detected. Figure 7 shows the Raman spectra recorded on the diamond coated $\mathrm{Mo} / \mathrm{Si}$ surfaces obtained by HF-CVD processing for 2 up to $80 \mathrm{~min}$ using $2.0 \%$ and $3.0 \% \mathrm{CH}_{4} / \mathrm{H}_{2}$ gas mixtures.

On all samples, five strong Raman signals can be distinguished in the range $1000-1800 \mathrm{~cm}^{-2}$. These are indicated by the numbers $2-6$, identical to the labeling used for the Raman signals in Fig. 2. For the NCD film formation using $2.0 \% \mathrm{CH}_{4}$, there are only relatively minor differences in the Raman spectra [Fig. 7(a)]. The sharp line centered at $1333 \mathrm{~cm}^{-1}$ (3) corresponds to crystalline diamond and is characterized by a full-width at half maximum equal to about $8 \mathrm{~cm}^{-1}$. There is a slight increase in the intensity of the Raman bands corresponding to the nondiamond carbon phases such as t-PA $(2,5)$ and graphitic carbon $(4,6)$ relative to the diamond peak, with increasing deposition time. This indicates a minor increase in the incorporation of nondiamond carbon phases at grain boundaries, for example, with increasing NCD film thickness. This is also supported by the slight deterioration in diamond crystallinity of the NCD films as a function of deposition time [see Figs. 6(c) and 6(e)]. On the other hand, the NCD films deposited from a gas mixture of 3.0\% $\mathrm{CH}_{4} / \mathrm{H}_{2}$ [see Fig. 7(b)] display increased levels of nondiamond carbon phases compared to the NCD films grown with $2.0 \% \mathrm{CH}_{4} / \mathrm{H}_{2}$. These $s p^{2}$-bonded carbons are found predominantly at grain boundaries, exhibiting a larger relative density in the case of smaller grained NCD layers. 

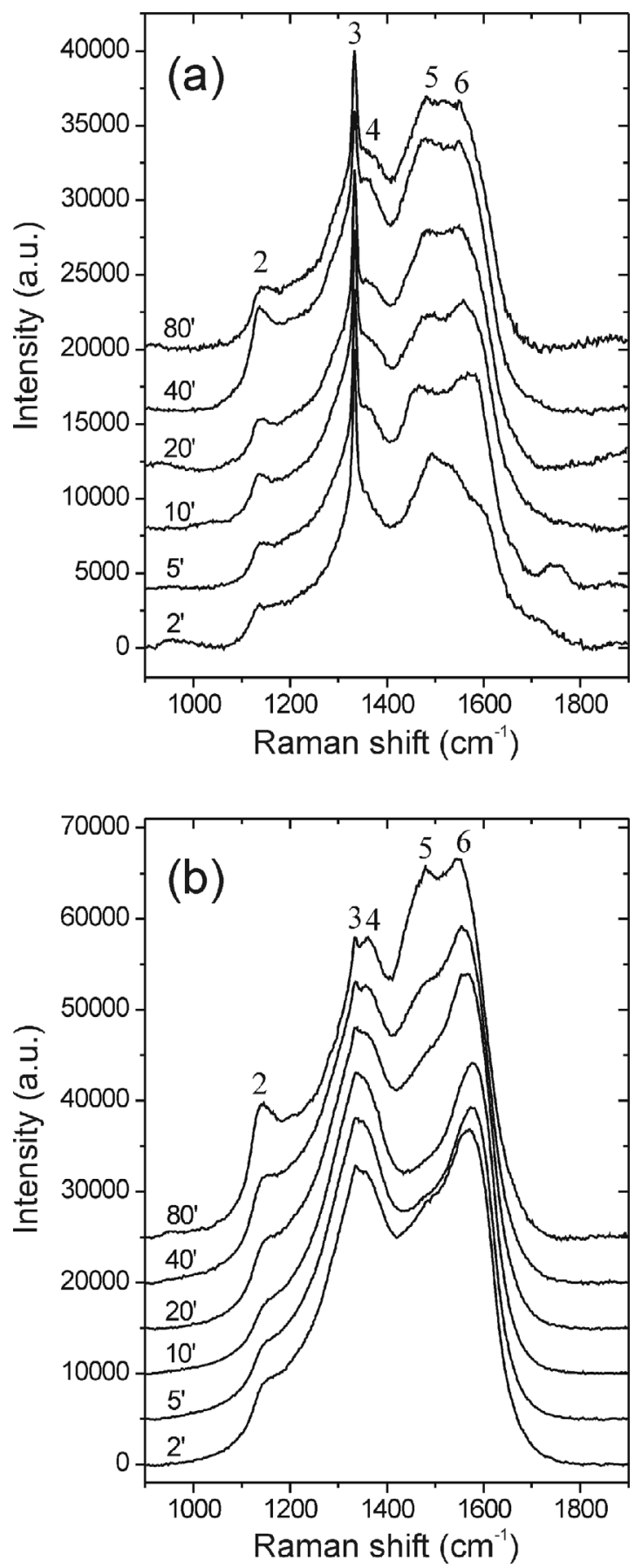

FIG. 7. Raman spectra recorded after various stages of NCD film formation on $\mathrm{Mo} / \mathrm{Si}$ using $\mathrm{CH}_{4} / \mathrm{H}_{2}$ gas flows of $2.0 \%$ (a) and $3.0 \%$ (b). The Raman signals numbered 2-6 correspond to the signals from t-PA (2 and 5), diamond (3), and the D-band (4) and G-band (6) of graphite, respectively.

The Raman bands originating from graphitic carbon $(4,6)$ are most pronounced, and, in particular, the bands related to t-PA $(2,5)$ gain somewhat in intensity at extended NCD film growth. Similar trends in Raman peak intensities were observed on NCD films grown on Si substrates in the absence of Mo interlayers (not shown), so that it may be concluded that the Mo interlayers do not induce higher levels of nondiamond carbon phases within the grown NCD films. In summary, Mo seed layers enhance the nucleation of diamond on Si substrates at low deposition temperature facilitating the growth of smooth NCD films without any deterioration of the carbon phase composition.

\section{CONCLUSIONS}

The nucleation enhancement of NCD films during HFCVD performed at a low substrate temperature of $550{ }^{\circ} \mathrm{C}$ was demonstrated. The surface modification of silicon substrates by a sputter deposition of $50 \mathrm{~nm}$ thick Mo layers followed by ultrasonic seeding using nanosized diamond particles, lead to an enhanced nucleation rate of diamond as compared to seeded but blank Si substrates. The enhanced nucleation of diamond is ascribed to a nanoscale roughening of the Mo surface that favors the embedding of diamond seeds and to the rapid carburization of the Mo layer that leads to the formation of $\mathrm{Mo}_{2} \mathrm{C}$ at the substrate surface. Consequently, a fast accumulation of carbon during the early stages of the diamond growth is obtained. The faster nucleation kinetics on Mo-coated surfaces yields diamond nucleation site densities up to about $5 \times 10^{10} \mathrm{~cm}^{-2}$ which are ten times higher than the ones observed on blank Si surfaces. We demonstrated that the use of Mo seed layers facilitates the growth of smooth and highly uniform NCD films with a rms surface roughness as low as $\sim 6 \mathrm{~nm}$.

\section{ACKNOWLEDGMENTS}

We would like to thank J. van Zijl (Philips Research Europe, The Netherlands) for the Mo sputtering. R. Hendrikx (Department of Materials Science and Engineering, Delft University of Technology) is acknowledged for the x-ray analysis. This research was supported by the Dutch Technology Foundation STW, the applied science division of NWO, and the Technology Program of the Ministry of Economic Affairs (Veni Grant No. NAF.7527). J.G.B. acknowledges financial support from the FWO (Science Foundation Flanders, Belgium, fellowship Contract No. SeniorGP.007.10N) and L.V. from MEC Project No. FIS200912964-C05-04 and CAM Project AVANSENS-CM No. S2009/PPQ-1642, respectively.

${ }^{1}$ P. W. May, Science 319, 1490 (2008).

${ }^{2}$ J. Philip, P. Hess, T. Feygelson, J. E. Butler, S. Chattopadhyay, K. H. Chen, and L. C. Chen, J. Appl. Phys. 93, 2164 (2003).

${ }^{3}$ A. V. Sumant, A. R. Krauss, D. M. Gruen, O. Auciello, A. Erdemir, M. Williams, A. F. Artiles, and W. Adams, Tribol. Trans. 48, 24 (2005).

${ }^{4}$ E. Wörner, C. Wild, W. Müller-Sebert, P. Koidl, and A. Bankewitz, Adv. Sci. Technol. (Faenza, Italy) 48, 142 (2006).

${ }^{5}$ J. E. Butler and A. V. Sumant, Chem. Vap. Deposition 14, 145 (2008).

${ }^{6}$ T. Shardaa and T. Sogab, J. Nanosci. Nanotechnol. 3, 521 (2003).

${ }^{7}$ T. Wang, H. W. Xin, Z. M. Zhang, Y. B. Dai, and H. S. Shen, Diamond Relat. Mater. 13, 6 (2004).

${ }^{8}$ D. M. Gruen, in Ultrananocrystalline Diamond: Synthesis, Properties and Applications, edited by O. A. Shenderova and D. M. Gruen (William Andrew, Norwich, 2006), Chap. 5, pp. 157-184.

${ }^{9}$ D. M. Gruen, Annu. Rev. Mater. Sci. 29, 211 (1999).

${ }^{10}$ N. N. Naguib, J. W. Elam, J. Birrell, J. Wang, D. S. Grierson, B. Kabius, J. M. Hiller, A. V. Sumant, R. W. Carpick, O. Auciello, and J. A. Carlisle, Chem. Phys. Lett. 430, 345 (2006).

${ }^{11}$ S. Z. Rotter and J. C. Madaleno, Chem. Vap. Deposition 15, 209 (2009).

${ }^{12}$ A. V. Sumant, P. U. P. A. Gilbert, D. S. Grierson, A. R. Konicek, M. Albrecht, J. E. Butler, T. Feygelson, S. S. Rotter, and R. W. Carpick, Diamond Relat. Mater. 16, 718 (2007).

${ }^{13}$ X. Y. Zhong, Y. C. Chen, N. H. Tai, I. N. Lin, J. M. Hiller, and O. 
Auciello, J. Appl. Phys. 105, 034311 (2009).

${ }^{14}$ H. A. Girard, S. Perruchas, C. Gesset, M. Chaigneau, L. Vieille, J.-C. Arnault, P. Bergonzo, J.-P. Boilot, and T. Gacoin, Appl. Mater. Interf. 1, 2738 (2009).

${ }^{15}$ J. G. Buijnsters, L. Vázquez, and J. J. ter Meulen, Diamond Relat. Mater. 18, 1239 (2009).

${ }^{16}$ O. A. Williams, O. Douhéret, M. Daenen, K. Haenen, E. Osawa, and M. Takahashi, Chem. Phys. Lett. 445, 255 (2007).

${ }^{17}$ O. Shenderova, S. Hens, and G. McGuire, Diamond Relat. Mater. 19, 260 (2010).

${ }^{18}$ M. Daenen, L. Zhang, R. Erni, O. A. Williams, A. Hardy, M. K. van Bael, P. Wagner, K. Haenen, M. Nesládek, and G. van Tendeloo, Adv. Mater (Weinheim, Ger.) 21, 670 (2009).

${ }^{19}$ J. G. Buijnsters, P. Shankar, and J. J. ter Meulen, Surf. Coat. Technol. 201, 8955 (2007).

${ }^{20}$ X. Xiao, B. W. Sheldon, E. Konca, L. C. Lev, and M. J. Lukitsch, Diamond Relat. Mater. 18, 1114 (2009).

${ }^{21}$ C. Barei $\beta$, M. Perle, S. M. Rosiwal, and R. F. Singer, Diamond Relat. Mater. 15, 754 (2006).

${ }^{22}$ F. J. G. Silva, A. J. S. Fernandes, F. M. Costa, A. P. M. Baptista, and E. Pereira, Diamond Relat. Mater. 13, 828 (2004).

${ }^{23}$ Q. H. Fan, A. Fernandes, and J. Gracio, Diamond Relat. Mater. 7, 603 (1998).

${ }^{24}$ J. M. Lopez, V. G. Babaev, V. V. Khvostov, and J. M. Albella, J. Mater. Res. 13, 2841 (1998).

${ }^{25}$ Y. S. Li, Y. Tang, Q. Yang, J. Maley, R. Sammynaiken, T. Regier, C. Xiao, and A. Hirose, Appl. Mater. Interf. 2, 335 (2010).

${ }^{26}$ L. J. Chen, N. H. Tai, C. Y. Lee, and I. N. Lin, J. Appl. Phys. 101, 064308 (2007).

${ }^{27}$ L. J. Chen, K. F. Liu, N. H. Tai, W. F. Pong, and I. N. Lin, Diamond Relat. Mater. 19, 134 (2010).

${ }^{28}$ J. G. Buijnsters, L. Vázquez, R. Escobar Galindo, and J. J. ter Meulen, J. Nanosci. Nanotechnol. 10, 2885 (2010).

${ }^{29}$ Y. Lifshitz, C. H. Lee, Y. Wu, W. J. Zhang, I. Bello, and S. T. Lee, Appl.
Phys. Lett. 88, 243114 (2006)

${ }^{30}$ J. E. Butler and I. Oleynik, Philos. Trans. R. Soc. London, Ser. A 366, 295 (2008).

${ }^{31}$ A. C. Ferrari and J. Robertson, Phys. Rev. B 63, 121405 (2001).

${ }^{32}$ J. Houška, N. R. Panyala, E. M. Peña-Méndez, and J. Havel, Rapid Commun. Mass Spectrom. 23, 1125 (2009).

${ }^{33}$ F. F. Abraham, Homogeneous Nucleation Theory: The Pretransition Theory of Vapour Condensation, Advances in Theoretical Chemistry (Academic, New York, 1974).

${ }^{34}$ T. Hao, H. Zhang, C. Shi, and G. Han, Surf. Coat. Technol. 201, 801 (2006).

${ }^{35}$ J. T. Drotar, Y.-P. Zhao, T.-M. Lu, and G.-C. Wang, Phys. Rev. E 59, 177 (1999).

${ }^{36}$ J. G. Buijnsters and L. Vázquez, Surf. Coat. Technol. 201, 8950 (2007).

${ }^{37}$ M. Sztucki, T. H. Metzger, I. Kegel, A. Tilke, J. L. Rouvière, D. Lübbert, J. Arthur, and J. R. Patel, J. Appl. Phys. 92, 3694 (2002).

${ }^{38}$ C. J. Rosa, Metall. Trans. A 14, 199 (1983).

${ }^{39}$ S. N. Mikhailov, D. Ariosa, J. Weber, Y. Baer, W. Hänni, X.-M. Tang, and P. Alers, Diamond Relat. Mater. 4, 1137 (1995).

${ }^{40}$ J. F. Fang, J. Huo, J. Y. Zhang, and Y. Zheng, Powder Diffr. 22, 319 (2007).

${ }^{41}$ J. G. Buijnsters, P. Shankar, W. J. P. van Enckevort, J. J. Schermer, and J. J. ter Meulen, Thin Solid Films 474, 186 (2005).

${ }^{42}$ R. L. Stolk, J. G. Buijnsters, J. J. Schermer, N. Teofilov, R. Sauer, M. J. Fransen, and J. J. ter Meulen, Diamond Relat. Mater. 12, 1322 (2003).

${ }^{43}$ J. G. Buijnsters, P. Shankar, W. J. P. van Enckevort, J. J. Schermer, and J. J. ter Meulen, Diamond Relat. Mater. 13, 848 (2004).

${ }^{44}$ B. Atakan, K. Lummer, and K. Kohse-Höinghaus, Phys. Chem. Chem. Phys. 1, 3151 (1999).

${ }^{45}$ D. F. Bahr, D. V. Bucci, L. S. Schadler, J. A. Last, J. Heberlein, E. Pfender, and W. W. Gerberich, Diamond Relat. Mater. 5, 1462 (1996).

${ }^{46}$ H. Sternschulte, H. E. Rabl, D. Steinmuller-Nethl, and B. Tilg, Chem. Vap. Deposition 14, 232 (2008). 